\title{
Terminal care in old age psychiatry: a survey of professionals' attitudes and approaches
}

\author{
JoSEPHine ANNe RichaRds, Registrar in Psychiatry, Towers Hospital, \\ Leicester LE5 OTD; and JAMES LindesAY, Professor of Psychiatry for the Elderly, \\ University of Leicester, Leicester General Hospital, Leicester LE5 4PW
}

Few clinical decisions are more difficult than whether or not to withhold treatment from patients who are unable to make this choice for themselves. This is because they bring into conflict a number of principles central to clinical practice, such as the duty to save life, the duty to relieve suffering, and the duty to heed patients' wishes. In North America, advance directives ('living wills') from patients, made when they are fully competent, have achieved considerable popularity in recent years as a possible way out of these dilemmas (La Puma et al, 1991; Molloy et al, 1991); unfortunately, it is by no means clear whether these can in fact provide a workable solution to the problem of treating incompetent patients (Hope, 1992). For the time being, decisions about withholding treatment will continue to be made by the health professionals immediately involved at the time, often junior staff with little experience or training, and there is a need for a professional consensus as to the factors that should be properly taken into consideration. This study investigates the current attitudes and approaches of psychiatrists and psychiatric nurses in one health district to this problem. It examines the criteria used, and the conditions under which decisions about administering or withholding treatments are being made.

\section{The study}

A questionnaire was designed which asked respondents to answer Yes or No as to whether they considered various specific factors important in the decision to withhold active medical interventions from elderly psychiatric in-patients who were also physically ill. The term "active medical intervention" was defined as including the following measures: cardiopulmonary resuscitation, intravenous or intramuscular medication (other than for pain relief or tranquillisation), intravenous fluid administration, transfer to another medical speciality (other than for relief of acute distress), and further physical investigations. Respondents were also asked whether, in their clinical practice, they were able to obtain adequate information when assessing these factors. They were then asked if they had received any guidance or training on decisions to withhold active medical intervention from elderly psychiatric patients, and if they felt confident in managing the pain relief of the dying patient. Finally, they were asked to give their personal definition of the term "quality of life".

The questionnaire was initially distributed to ten nursing and medical professionals in a pilot study, and the questionnaire was modified on the basis of their replies and comments; specifically, more factors considered relevant by the pilot respondents were added.

The final questionnaire was then sent to all consultants and senior registrars in general adult psychiatry and old age psychiatry within the Leicestershire health district, all registrars and senior house officers in psychiatry working in the area, and all staff nurses and state enrolled nurses working on wards for the elderly mentally ill, both long-stay and acute assessment. Although this study was concerned with the psychogeriatric patient, it was considered important to canvas the opinions of those medical staff in other psychiatric specialties who might be involved in decisions about withholding treatment from elderly patients in the course of their out-ofhours on-call duties.

The 16 factors included in the questionnaire were: psychiatric diagnosis; age; general physical health; nature of present physical illness; degree of dependency in activities of daily living; patients' views; relatives' views; ward nurses' views; views of other members of the multidisciplinary team; number of previous treatments for present physical illness; length of previous treatments for present physical illness; short length of this admission; long length of this admission; respondent's own religious or ideological views; medico-legal considerations; and cost-benefit considerations. The questionnaires were distributed and returned over a three month period. Respondents were asked to state their professional designation and grade, but replies were otherwise anonymous.

\section{Findings}

Two hundred questionnaires were distributed and 107 returned, giving an overall response rate of $54 \%$. 
Response rates for all nurses were $46 \%(n=57)$ and all doctors $67 \%(n=50)$.

The following factors were considered important by all grades of respondent at the frequencies shown: present physical illness $(97 \%)$, general physical health $(93 \%)$, relatives' views $(94 \%)$, patients' views $(87 \%)$, ward nurses' views $(84 \%)$, views of other members of the multidisciplinary team $(82 \%)$ and medico-legal considerations (75\%). Conversely, factors not considered important by any grade of nurses or doctors were: length of admission (72\% No) and cost-benefit considerations ( $77 \%$ No).

There was no consensus among the respondents in respect of the importance attributed to the following variables when making the decision whether or not to withhold treatment: for age the overall Yes:No ratio was $51 \%: 48 \%$; for number and length of previous treatments for present physical illness, the ratio was $50 \%: 49 \%$; for the degree of dependency in activities of daily living, the ratio was $50 \%: 40 \%$; and for the professionals' own views, the ratio was $51 \%: 45 \%$. There were no significant differences between doctors and nurses in the responses to these items.

In some respects, doctors and nurses did differ in their views: 38 doctors $(76 \%)$ and 29 nurses $(51 \%)$ considered the psychiatric diagnosis to be important in the decision to withhold treatment, whereas 12 $(24 \%)$, and $28(49 \%)$ respectively, answered No to this item $(P<0.02)$.

Of the factors deemed important, respondents felt that they were able to obtain adequate information about all except patients' views and medico-legal aspects. (Yes: No ratios of $22 \%: 49 \%$ and $25 \%: 37 \%$ respectively). Fewer doctors (22\%) than nurses (47\%) believed they could obtain adequate information about relatives' views $(P<0.001)$. Junior doctors (registrars/senior house officers) reported that they were less able than consultants and nursing staff to obtain adequate information about the views of other members of the multidisciplinary team $(P<0.01)$.

Thirty-two respondents $(30 \%)$ stated that they had received guidance on withholding treatments from psychogeriatric patients and $71(66 \%)$ had not.

Fifty-seven respondents (53\%) felt confident in managing the pain relief of the dying patient and 45 (42\%) did not.

Replies to the open question about quality of life were broadly consistent, and fell into two broad categories. Physical aspects given were: freedom from pain, good physical health, financial security, self-care abilities, degree of mobility, physical comfort, and continence. Psychological and spiritual aspects included: cognitive stage, ability to communicate, independence, capacity for enjoyment, dignity, ability to interact meaningfully with others, self-esteem, mood, possessing values and attitudes, hopes for the future, and freedom from political oppression.

\section{Comment}

The response rate in this study was lowest among nurses, which may be explained by the following comments elicited from a randomly selected group of eight non-responders: two stated that they were too busy, three that the decision was a medical one and therefore did not involve them, and three reported that they did not understand the questions. Despite the relatively low response from nurses, the overall response rate of $54 \%$ is reasonable for postal surveys of this type, and allows some conclusions to be drawn. The questionnaire was relatively long but, as the pilot study had indicated, this is not an issue which can be readily condensed into a small number of variables.

Inevitably, decisions about withholding treatment from patients depend crucially on the particular circumstances of individual cases, and cannot be reduced by research to a matter of checklists and algorithms. However, it is also important that there should be some uniformity in the professional judgements that are brought to bear on this issue, to ensure that the outcome in such situations does not depend on accidents of timing or geography (Oppenheimer, 1991). This study has examined the extent to which a professional consensus on this issue currently exists in one health district. Overall, there was good agreement that the patient's general physical health, the nature of any physical illness, patients', relatives', ward nurses' and other team members' views and medico-legal considerations were important, and that the length of admission and cost-benefit considerations were not important, in making decisions about whether or not to withhold treatment. This is encouraging, and suggests that these factors could form the basis of a useful advisory framework in developing local policies and guidelines to promote good standards in clinical practice.

However, in developing such guidelines, it will be necessary to address the important areas of professional disagreement identified in this survey. It is of some concern that there was no consensus as to whether age or degree of dependency in activities of daily living were important in decisions about withholding treatment, and that there was a significant difference between doctors and nurses as to the importance of the psychiatric diagnosis in this process. These findings suggest that some education and debate on these issues is needed; in particular, all doctors and nurses working with the elderly need to understand that age alone is not a reason for withholding active medical intervention, all other factors being equal.

There is also a need to look at areas where the information on which to base decisions on terminal care may be lacking or hard to obtain when needed (i.e. on a back ward at dead of night). Important 
factors in this respect in this survey were patients' views and medico-legal aspects; most respondents considered these important, but many felt that they did not know enough. Similarly, doctors thought they had a poorer understanding of the relatives' views than did nurses, and the junior doctors also considered that they were less aware of the views of other members of the multidisciplinary team than other professionals. These findings could reflect either a real lack of information or poor communication, and require further study.

Freedom from pain was identified as an important aspect of quality of life by many respondents; however, a substantial minority of respondents were not confident in managing the pain relief of the dying patient. Neither psychiatrists nor psychiatric nurses currently receive any special training in this aspect of what has been described as the "terminal care of psychogeriatric in-patients" (Black \& Jolley, 1990). Further education in analgesia could usefully be incorporated into psychiatric training of both professions.

\section{Acknowledgements}

We are grateful to all our colleagues who participated in the study.

\section{References}

Black, D. \& JolleY, D. (1990) Slow euthanasia? The deaths of psychogeriatric patients. British Medical Journal, 300, 1321-1323.

Hope, T. (1992) Advance directives about medical treatment. British Medical Journal, 304, 398.

La Puma, J., Orentrlicher, D. \& Moss, R. J. (1991) Advance directives on admission. Journal of the American Medical Association, 266, 402-405.

Molloy, D. W., Clarnette, R. M., Braun, E. A., Eismann, M. R. \& Sneidermann, B. (1991) Decision making in the incompetent elderly: "The daughter from California syndrome". Journal of the American Geriatrics' Society, 39, 396-399.

OPPENHEIMER, C. (1991) Ethics and the psychiatry of old age. In Psychiatry in the Elderly (eds. R. Jacoby and C. Oppenheimer). Oxford: Oxford University Press.

\title{
Survey of undergraduate teaching of old age psychiatry in the United Kingdom
}

\author{
Gabrielle M. Fatre, Senior Registrar in Psychiatry, Mental Health Unit, \\ Basildon Hospital, Basildon SS16 5NL; and CoRnelius L. E. KaTONA, Professor of \\ Psychiatry of the Elderly, Department of Psychiatry, University College London \\ School of Medicine, Wolfson Building, Middlesex Hospital, London WIN 8AA
}

Old age psychiatry has been steadily developing as a specialty in the United Kingdom. In 1978 the Royal College of Psychiatrists established a specialist section for old age psychiatry, and since October 1989 it has been formally recognised as a sub-specialty of psychiatry. In 1989 the Royal College of Physicians and the Royal College of Psychiatrists published a joint report entitled 'Care of Elderly People with Mental Illness' in which recommendations were made about both postgraduate and undergraduate training.

The recommendations concerning postgraduate training have in the main been adopted by the Joint Committee in Higher Psychiatric Training, who published a revised position statement on training in old age psychiatry in November 1989. With respect to undergraduate education the joint report commented that "there is little information as to the quality and context of students' exposure in the different medical schools". The report recommended that each medical school should have a senior academic post in old age psychiatry, and that all medical students should receive training in old age psychiatry, with consideration given to integrating teaching with that given in geriatric medicine.

\section{The study}

In this survey, we aimed to explore the current state of undergraduate teaching in the subject, to see the extent to which these recommendations are being met, and to identify differences in teaching offered by the 27 medical schools currently providing undergraduate training in old age psychiatry. 